\title{
Patency of Hemashield grafts versus ringed Gore-Tex grafts in middle hepatic vein reconstruction for living donor liver transplantation
}

\author{
Sang Hoon Kim, Shin Hwang, Minjae Kim, Tae-Yong Ha, Gi-Won Song, Dong-Hwan Jung, \\ Chul-Soo Ahn, Deok-Bog Moon, Ki-Hun Kim, Gil-Chun Park, and Sung-Gyu Lee \\ Division of Hepatobiliary Surgery and Liver Transplantation, Department of Surgery, \\ Asan Medical Center, University of Ulsan College of Medicine, Seoul, Korea
}

\begin{abstract}
Backgrounds/Aims: Owing to the short supply of homologous vein allografts, we previously used ringed Gore-Tex vascular grafts for middle hepatic vein (MHV) reconstruction in living donor liver transplantation. When ringed Gore-Tex grafts became unavailable, we used Hemashield vascular grafts. This study aimed to compare the patency and complication rates of Hemashield and ringed Gore-Tex grafts. Methods: This retrospective two-arm study compared the study group that received Hemashield grafts $(n=157)$ and the propensity score-matched control group that received ringed Gore-Tex grafts $(n=157)$. Results: In the Hemashield and Gore-Tex groups, the recipient age was $54.7 \pm 9.4$ and

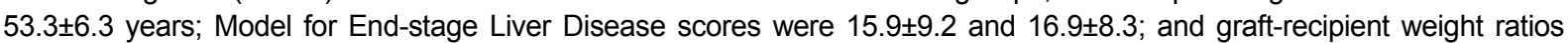
were $1.07 \pm 0.24$ and $1.10 \pm 0.23$, respectively. In the Hemashield group, V5 reconstruction was performed using single $(n=113,72.0 \%)$, double $(n=39,24.8 \%)$, and triple $(n=3,1.9 \%)$ anastomoses. The proportion of double and triple anastomoses for V5 and V8 was higher in the Hemashield group than in the Gore-Tex group. Two (1.3\%) patients required MHV conduit stenting owing to early thrombosis of the Hemashield graft. There was no difference in conduit occlusion-free patient survival rates between groups $(p=0.91)$. The incidence of accidental conduit migration in the Hemashield and Gore-Tex groups was $0(0 \%)$ and $2(1.3 \%)$, respectively. Conclusions: Hemashield grafts used in MHV reconstruction demonstrated acceptably high short- and mid-term patency rates, no incidences of conduit migration, easy handling, and good flexibility for length adjustment. Therefore, we suggest that the Hemashield graft is the preferentially suitable prosthetic material for MHV reconstruction. (Ann Hepatobiliary Pancreat Surg 2021;25:46-53)
\end{abstract}

Key Words: Prosthetic graft; Hepatic venous congestion; Patency; Thrombosis; Graft migration

\section{INTRODUCTION}

Middle hepatic vein (MHV) reconstruction with vascular graft interposition has been accepted as a standard procedure for living donor liver transplantation (LDLT) using modified right lobe grafts. Various vascular conduit materials have been used for this procedure. ${ }^{1-4}$ Sizable vein allografts recovered from deceased organ or tissue donors are ideal materials for MHV reconstruction, but their supply does not meet the demand, especially in countries where LDLT is frequently performed.

Prosthetic vascular grafts are alternatives to sizable vein allografts, with comparable patency. ${ }^{5-7}$ There are many types of commercially available prosthetic vascular grafts; thus, it is important to determine the most suitable graft for MHV reconstruction. We have previously reported longterm patency rates of MHV reconstruction using ringed expanded polytetrafluoroethylene (ePTFE; Gore-Tex vascular graft, Gore Medical; Newark, DE, USA; hereafter referred to as Gore-Tex) grafts. ${ }^{5,6}$ Since ringed Gore-Tex grafts became unavailable in Korea due to discontinuation of the product, we have used collagen-impregnated woven double-velour polyester (Hemashield Platinum, Maquet; Rastatt, Germany; hereafter referred to as Hemashield) grafts. ${ }^{6,7}$

We have reported the short-term patency rates of MHV reconstruction using Hemashield vascular grafts in a pre-

Received: January 11, 2021; Revised: February 1, 2021; Accepted: February 2, 2021

Corresponding author: Shin Hwang

Department of Surgery, Asan Medical Center, University of Ulsan College of Medicine, 88 Olympic-ro 43-gil, Songpa-gu, Seoul 05505, Korea Tel: +82-2-3010-3930, Fax: +82-2-3010-6701, E-mail: shwang@amc.seoul.kr

Copyright (C) 2021 by The Korean Association of Hepato-Biliary-Pancreatic Surgery

This is an Open Access article distributed under the terms of the Creative Commons Attribution Non-Commercial License (http://creativecommons.org/ censes/by-nc/4.0) which permits unrestricted non-commercial use, distribution, and reproduction in any medium, provided the original work is properly cited. Annals of Hepato-Biliary-Pancreatic Surgery - pISSN: 2508-5778 - elSSN: 2508-5859 
vious study; ${ }^{6}$ however, the sample size was too small and follow-up period was too short to fully assess the suitability of Hemashield grafts for MHV reconstruction. Therefore, in this study, we aimed to compare the shortand mid-term patency rates and complications of Hemashield and ringed Gore-Tex grafts in MHV reconstruction.

\section{MATERIALS AND METHODS}

\section{Study design}

This was a retrospective two-arm observational study of the outcomes of Hemashield and ringed Gore-Tex graft interposition in MHV reconstruction. The primary purpose of this study was to determine the short- and mid-term patency rates of Hemashield grafts, and the secondary purpose was to assess the incidence of Hemashield graftassociated complications.

To assess the outcomes of Hemashield graft interposition, we selected all patients who underwent MHV reconstruction using Hemashield grafts during a 26-month study period from November 2017 to December 2019 (Hemashield group; $n=157$ ). As a control group, we selected an equal number of patients who underwent MHV reconstruction using ringed Gore-Tex grafts during a 48 month period from January 2011 to December 2014 using 1:1 propensity score matching (Gore-Tex group; $n=157$ ). The patency of ringed Gore-Tex grafts was used as reference data for prosthetic vascular grafts; thus, we selected
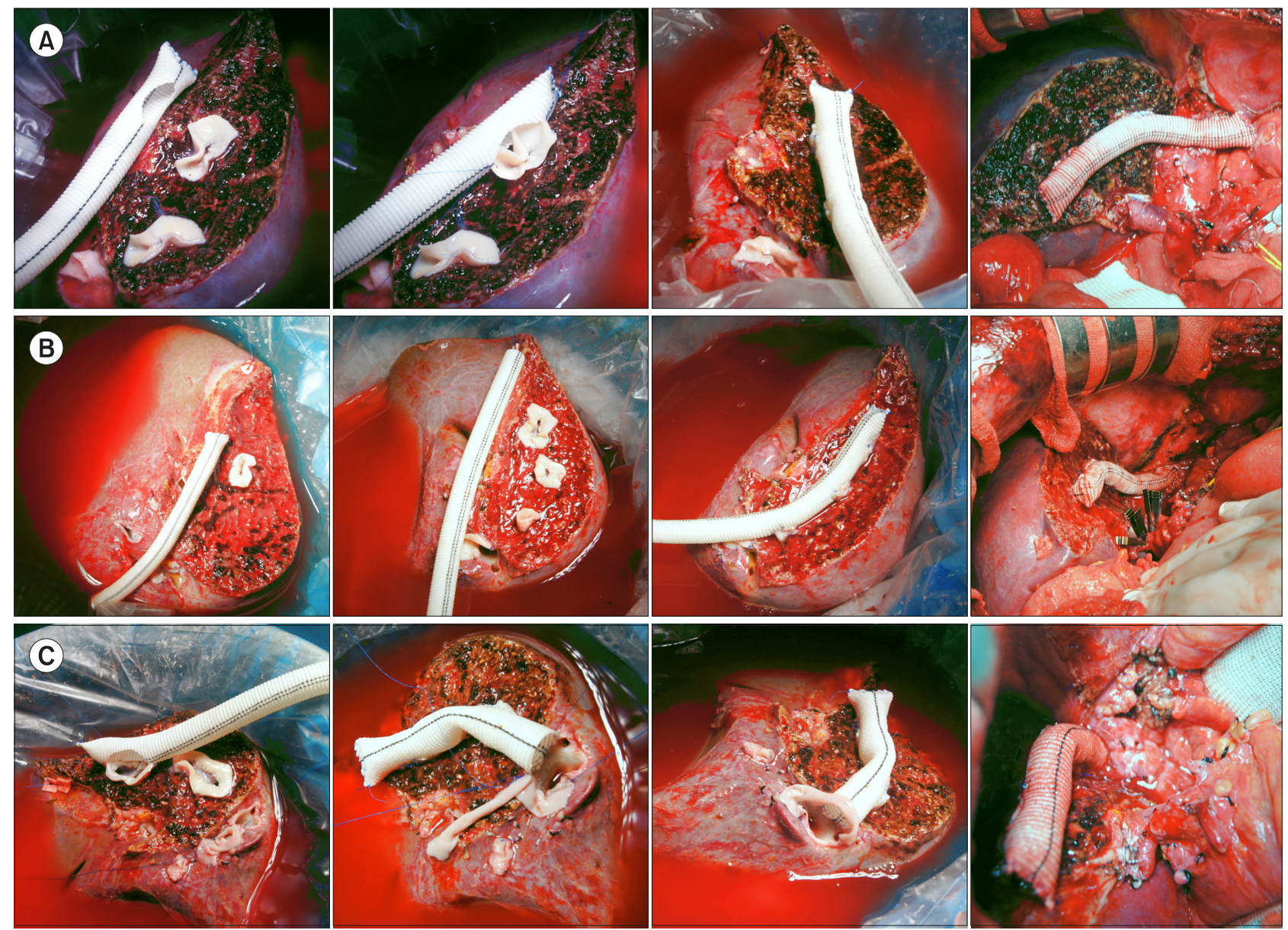

Fig. 1. Intraoperative photographs showing techniques for middle hepatic vein reconstruction using a Hemashield vascular graft. (A) Vascular patches are attached at the V5 and V8 openings, and a 12-mm Hemashield graft is anastomosed on the back table. The conduit is anastomosed to the recipient's inferior vena cava (IVC) in a side-to-end fashion. (B) A 10-mm Hemashield graft is attached to the liver graft using a single or double V5 anastomosis and a single V8 anastomosis, and this is anastomosed to the recipient's IVC in an end-to-end fashion. (C) A 12-mm Hemashield graft is attached to the liver graft with a single V5 anastomosis and a single V8 anastomosis, and this is conjoined with the liver graft's right hepatic vein orifice. A saphenous vein patch is attached around the conjoined orifice. The conjoined right and middle hepatic vein orifice is anastomosed to the recipient's IVC. 
patients who survived for at least 2 years without hepatocellular carcinoma recurrence. Patients in both groups were followed up until the end of August 2020.

The study protocol was approved by the Institutional Review Board of our institution (IRB No. 2019-1347), which waived the requirement for informed consent owing to the retrospective nature of the study. This study was performed in accordance with the ethical guidelines of the 2013 World Medical Association Declaration of Helsinki.

\section{Selection of prosthetic vascular grafts for MHV reconstruction}

After establishing the techniques for MHV reconstruction in 1997, we have attempted to reconstruct most of the MHV branches with a diameter of $\geq 5 \mathrm{~mm}$, including the segment $\mathrm{V}$ vein (V5) and the segment VIII vein (V8). The indications for MHV reconstruction have been described elsewhere. ${ }^{1-6}$ Previously, when large-sized vessel allografts were not available at our institutional tissue bank, we used 10-mm or 12-mm ringed Gore-Tex grafts. Subsequently, during the study period, ringed Gore-Tex grafts were no longer available; hence, we used $10-\mathrm{mm}$ or 12-mm Hemashield grafts. The indications for the use of Hemashield grafts were the same as those for the use of ringed Gore-Tex grafts.

\section{Surgical techniques for MHV reconstruction}

We used the same surgical techniques for MHV reconstruction regardless of the graft type. A prosthetic vascular graft with an internal diameter of 10-12 mm was selected. After making a small cut to enlarge the orifice of the V5 or V8 stump, a bridging allograft patch was attached for end-to-side anastomosis of the MHV branch (Fig. 1). ${ }^{5,6}$

If the orifice diameter of V5 or V8 was $>8 \mathrm{~mm}$ and the stump cuff of the V5/V8 orifice was thick, a Hemashield graft was directly anastomosed to the V5/V8 orifice without placing a bridging allograft patch.

We used three different methods to anastomose the Hemashield graft to the inferior vena cava (IVC) opening end-to-end anastomosis, side-to-end anastomosis, and oblique cutting of the conduit end and patch venoplasty (Fig. 2). The anastomosis method was selected according to the relative alignment of the Hemashield graft and the IVC and the surgeon's preference.
A
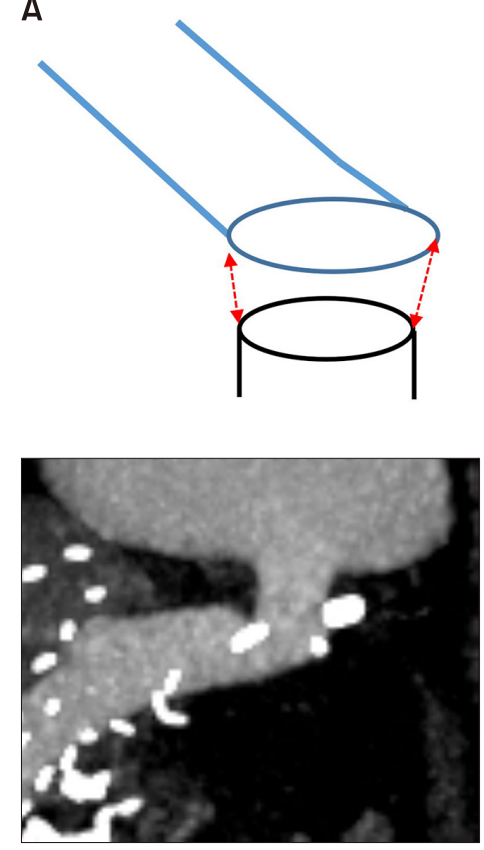

B
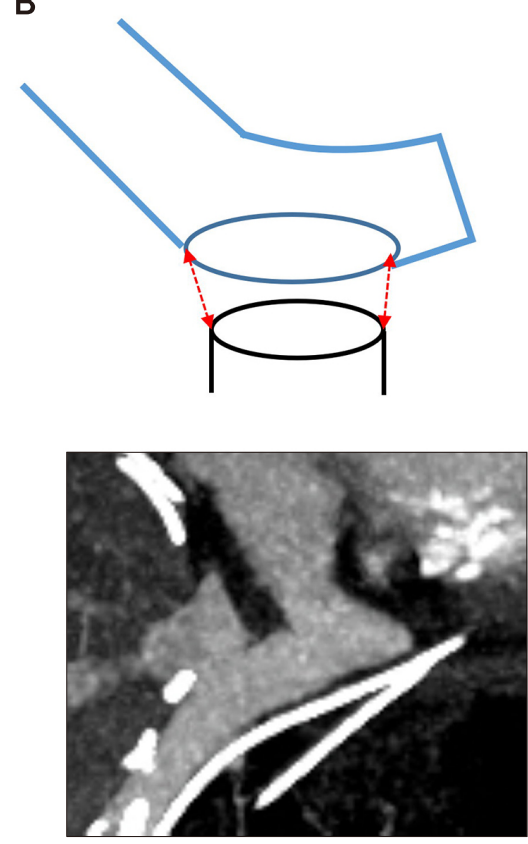

C
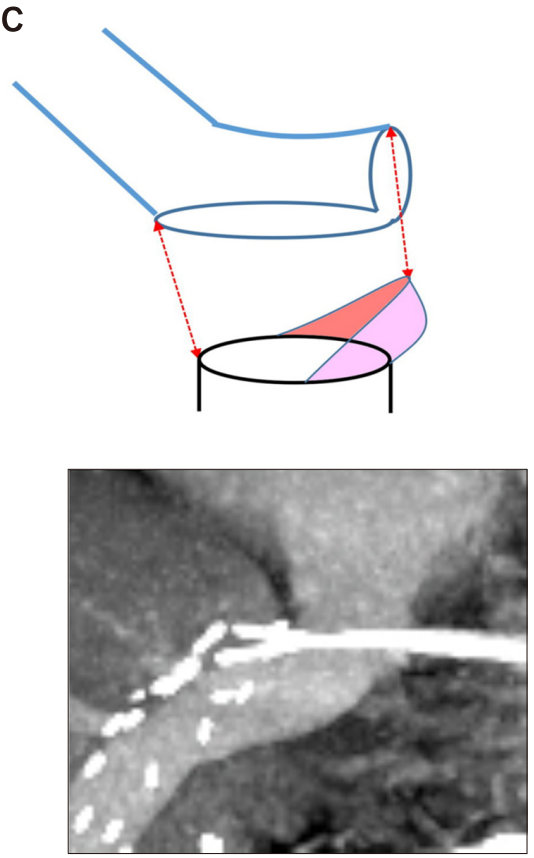

Fig. 2. Schematic illustration of reconstruction techniques for anastomosis of a Hemashield graft conduit to the recipient's left-middle hepatic vein trunk stump. There are three types of anastomosis: (A) end-to-end anastomosis, (B) side-to-end anastomosis, and (C) oblique cutting of the conduit end and patch venoplasty. The colored area represents a vein patch. 


\section{Evaluation of MHV-interposed prosthetic graft patency and indications for interventional stenting}

After the transplant, dynamic computed tomography (CT) was performed weekly during hospitalization and every 3-6 months thereafter at the outpatient clinic for the first 3 years. Thereafter, follow-up CT was performed annually for 5 years and biannually after 5 years. CT scan was performed more frequently in patients diagnosed with hepatocellular carcinoma.

We defined occlusion of the MHV conduit as non-visualization of blood flow in the prosthetic graft conduit between V8 (or V5 in cases where only V5 was reconstructed) and the IVC on liver CT. In cases where V5 was occluded but V8 remained patent, we considered the MHV conduit to be patent. In cases where it was not possible to perform CT owing to impaired renal function, Doppler ultrasonography was performed.

Interventional stenting of the thrombosed MHV conduit was indicated if significant MHV conduit occlusion-associated perfusion abnormality occurred in the graft liver., Interventional conduit stenting was regarded as conduit graft occlusion, regardless of the post-stenting patency.

\section{Statistical analysis}

The parameters for propensity score matching were recipient age and sex, Model for End-stage Liver Disease score, graft-recipient weight ratio, and number of V5/V8 anastomoses. All numerical data are presented as mean values with standard deviations. Continuous variables were compared using Student's $t$-test, and frequency variables were compared using the chi-square test or Fisher's exact test. Patency rates were determined using the KaplanMeier method and were compared using the log-rank test. A $p$-value of $<0.05$ was considered statistically significant. Statistical analyses were performed using SPSS version 22 (IBM; New York, NY, USA).

\section{RESULTS}

\section{Patient profiles}

The clinical profiles of all 314 patients who underwent LDLT using a modified right lobe graft along with MHV reconstruction using either Hemashield or ringed GoreTex vascular grafts are summarized in Table 1. In the Hemashield and Gore-Tex groups, the mean recipient age was $54.7 \pm 9.4$ and $53.3 \pm 6.3$ years; the frequency of hep-

Table 1. Clinical profiles of patients who underwent middle hepatic vein reconstruction using hemashield or Gore-Tex vascular grafts

\begin{tabular}{|c|c|c|c|}
\hline & Hemashield group & Gore-Tex group & $p$-value \\
\hline Patients (n) & 157 & 157 & \\
\hline Age (years) & $54.7 \pm 9.4$ & $53.3 \pm 6.3$ & 0.12 \\
\hline $\operatorname{Sex}(n)$ & & & 0.9 \\
\hline Male & $114(72.6 \%)$ & $115(73.2 \%)$ & \\
\hline Female & $43(27.4 \%)$ & $42(26.8 \%)$ & \\
\hline MELD score & $15.9 \pm 9.2$ & $16.9 \pm 8.3$ & 0.47 \\
\hline Primary disease (n) & & & $0.002 *$ \\
\hline HBV infection & $74(47.1 \%)$ & $102(65.0 \%)$ & \\
\hline $\mathrm{HCV}$ infection & $9(5.7 \%)$ & $7(4.5 \%)$ & \\
\hline Alcoholic liver disease & $51(32.5 \%)$ & $25(15.9 \%)$ & \\
\hline Cryptogenic cirrhosis & $10(6.4 \%)$ & $12(7.6 \%)$ & \\
\hline Acute liver failure & $5(3.2 \%)$ & $5(3.2 \%)$ & \\
\hline Autoimmune hepatitis & $3(1.9 \%)$ & $1(0.6 \%)$ & \\
\hline Primary sclerosing cholangitis & $3(1.9 \%)$ & $1(0.6 \%)$ & \\
\hline Wilson's disease & $2(1.3 \%)$ & $2(1.3 \%)$ & \\
\hline Polycystic liver disease & 0 & $2(1.3 \%)$ & \\
\hline Concurrent hepatocellular carcinoma (n) & $80(50.9 \%)$ & $77(49.1 \%)$ & 0.74 \\
\hline ABO-incompatible transplantation (n) & $28(17.8 \%)$ & $26(16.6 \%)$ & 0.77 \\
\hline Graft-recipient weight ratio & $1.07 \pm 0.24$ & $1.10 \pm 0.23$ & 0.26 \\
\hline
\end{tabular}

* Represents comparison between HBV infection and other primary diseases

MELD, model for end-stage liver disease; HBV, hepatitis $\mathrm{B}$ virus; $\mathrm{HCV}$, hepatitis $\mathrm{C}$ virus 
atitis B virus infection was 74 (47.1\%) and 102 (65.0\%); the Model for End-stage Liver Disease score was 15.9 \pm 9.2 and 16.9 \pm 8.3 ; the frequency of ABO-incompatible LDLT was $28(17.8 \%)$ and $26(16.6 \%)$; and the graft-recipient weight ratio was $1.07 \pm 0.24$ and $1.10 \pm 0.23$, respectively. Except primary liver diseases, all the investigated parameters were similar between groups.

\section{Configurations of MHV reconstruction using prosthetic vascular grafts}

All the available types of vessel fragment, including cryopreserved iliac arteries and veins and autologous saphenous and portal veins, were used for vessel patches that were attached to the V5/V8 orifices. Patch unification of two or three small V5/V8 orifices was preferentially performed because it enabled the performance of a single anastomosis to the interposed prosthetic graft.

In the Hemashield graft group, V5 reconstruction was performed with a single anastomosis in 113 patients (72.0\%, including unification venoplasty), double anastomoses in 39 patients $(24.8 \%)$, and triple anastomoses in 3 patients $(1.9 \%)$. V8 reconstruction was performed with a single anastomosis in 124 patients (79.0\%, including unification venoplasty), double anastomoses in 20 patients $(12.7 \%)$, and triple anastomoses in 2 patients (1.3\%). These configurations of V5 and V8 reconstruction are summarized in Table 2. The internal diameter of the Hemashield graft was $10 \mathrm{~mm}$ in 102 cases $(65.0 \%)$ and $12 \mathrm{~mm}$ in 55 cases $(35.0 \%)$.

Table 2. Configurations of middle hepatic vein reconstruction performed using Hemashield or ringed Gore-Tex vascular grafts

\begin{tabular}{ccc}
\hline & $\begin{array}{c}\text { Hemashield } \\
\text { group } \\
(\mathrm{n}=157)\end{array}$ & $\begin{array}{c}\text { Gore-Tex } \\
\text { group } \\
(\mathrm{n}=157)\end{array}$ \\
\hline V5 reconstruction $(\mathrm{n})$ & & \\
No reconstruction & $2(1.3 \%)$ & $5(3.2 \%)$ \\
Single anastomosis & $113(72.0 \%)$ & $128(81.5 \%)$ \\
Double anastomoses & $39(24.8 \%)$ & $24(15.3 \%)$ \\
Triple anastomoses & $3(1.9 \%)$ & 0 \\
V8 reconstruction (n) & $11(7.0 \%)$ & $37(23.6 \%)$ \\
No reconstruction & $124(79.0 \%)$ & $119(75.8 \%)$ \\
Single anastomosis & $20(12.7 \%)$ & $1(0.6 \%)$ \\
Double anastomoses & $2(1.3 \%)$ & 0 \\
Triple anastomoses & 2 & 0 \\
\hline
\end{tabular}

V5, liver segment $\mathrm{V}$ vein; V8, liver segment VIII vein
In the ringed Gore-Tex group, V5 reconstruction was performed with a single anastomosis in 128 patients (81.5\%, including unification venoplasty) and double anastomoses in 24 patients (15.3\%). V8 reconstruction was performed with a single anastomosis in 119 patients (75.8\%, including unification venoplasty) and double anastomoses in 1 patient $(0.6 \%)$ (Table 2). The internal diameter of the Gore-Tex vascular graft was $10 \mathrm{~mm}$ in 149 cases $(94.9 \%)$ and $12 \mathrm{~mm}$ in 8 cases $(5.1 \%)$.

The proportion of double and triple anastomose for V5 or V8 was higher in the Hemashield group than in the ringed Gore-Tex group ( $p=0.009$ for V5 and $p<0.001$ for V8) because it was less technically challenging to make multiple anastomoses with the Hemashield grafts than

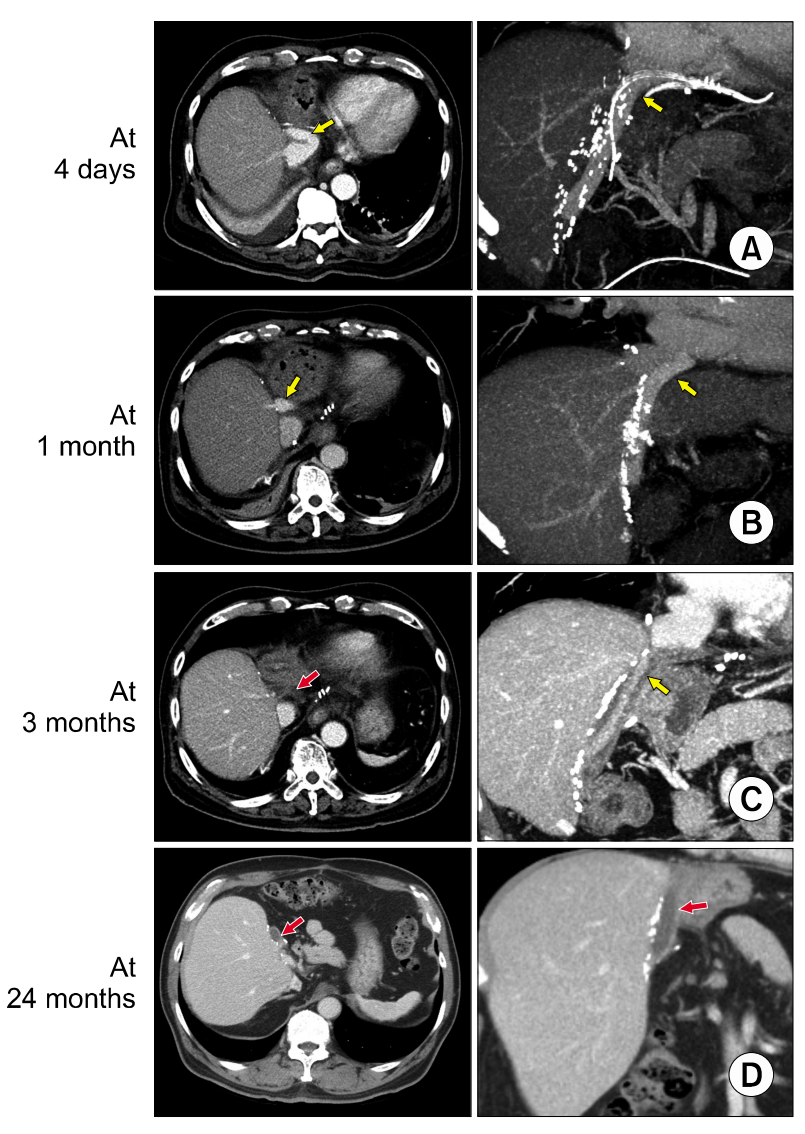

Fig. 3. Serial computed tomography (CT) images showing progressive occlusion of the lumen within the interposed Hemashield graft. Liver CT scans were performed at: (A) 4 days, (B) 1 month, (C) 3 months, and (D) 24 months after transplantation. Middle hepatic vein outflow was nearly completely occluded around 3 months, but no hepatic venous congestion occurs, due to the development of intrahepatic venous collaterals. The thrombosed Hemashield graft conduit is visible (D). Yellow arrows indicate luminal blood flow within the interposed Hemashield graft. Red arrows indicate the thrombus-filled Hemashield graft conduit. 
with the ringed Gore-Tex grafts.

\section{Sequences of prosthetic graft occlusion}

Serial follow-up CT scans showed that luminal occlusion occurred within the prosthetic grafts around the V5 anastomosis. V5 outflow was gradually reduced, which resulted in concentric thickening of the luminal thrombus. Consequently, the prosthetic graft with an original internal diameter of $10 \mathrm{~mm}$ or $12 \mathrm{~mm}$ was transformed into a narrow conduit with a small inner diameter. Thereafter, the lumen of the graft conduit between the V5 and V8 orifices was occluded. V8 outflow was maintained for a longer period than V5 outflow. The progression of MHV conduit occlusion that occurred after using a Hemashield graft is depicted in Fig. 3. The sequence of progressive occlusion of the interposed ringed Gore-Tex vascular graft has been reported previously.,

\section{Patency of prosthetic graft conduits}

During posttransplant follow-up, 3 patients in the Hemashield group died (in-hospital mortality) within 3 months. The Hemashield conduits in these patients were patent until patient death, according to their final follow-up imaging studies.

In the Hemashield graft group, 2 (1.3\%) patients required MHV conduit stenting owing to early thrombosis of the conduit. The suspected site of stenosis in these patients was the anastomosis site between the conduit and IVC. These patients underwent early stenting at posttransplant days 1 and 3, and the patency of the MHV conduit was restored. The conduit occlusion-free patient survival rates in the Hemashield group were $94.9 \%$ at 3 months, $88.9 \%$ at 6 months, $55.3 \%$ at 12 months, and $26.1 \%$ at 24 months (Fig. 4).

In the ringed Gore-Tex graft group, 4 patients $(2.5 \%)$ required MHV stenting. These patients underwent early stenting within 3 weeks of liver transplant (LT), and the MHV flow was successfully restored. The conduit occlusion-free patient survival rates in the ringed Gore-Tex group were $93.0 \%$ at 3 months, $79.0 \%$ at 6 months, $57.3 \%$ at 12 months, and $47.1 \%$ at 24 months, which were similar to those in the Hemashield group (Fig. 4, $p=0.91$ ).

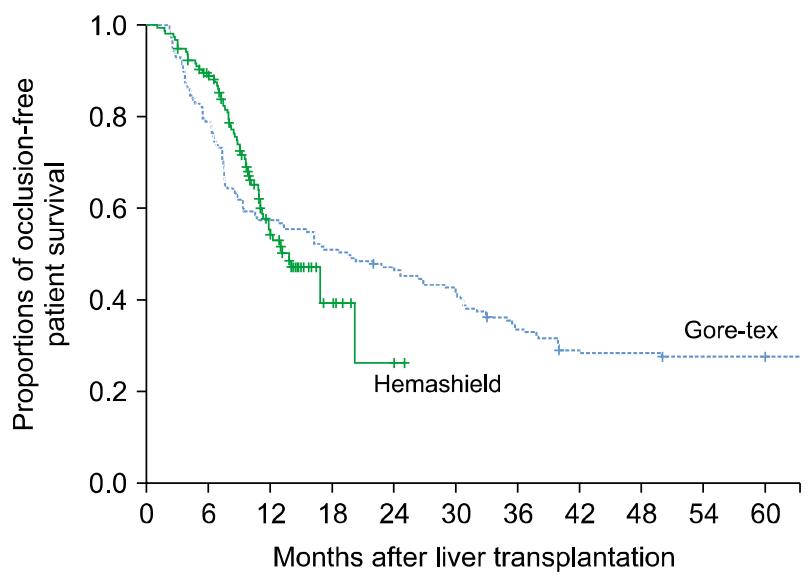

Fig. 4. Comparison of occlusion-free patient survival curves for different prosthetic vascular graft materials.

\section{Prosthetic vascular graft-associated complications}

In the Hemashield graft group, no accidental migration of the conduit graft into adjacent visceral structures occurred over a mean follow-up period of $14.5 \pm 5.9$ months. In contrast, in the ringed Gore-Tex graft group, there were 2 cases of accidental migration of the graft into the gastric wall at 6 months and 3 years after $\mathrm{LT},{ }^{6,10}$ resulting in an incidence of $1.3 \%$ over a mean follow-up period of 108.7 \pm 13.4 months. These 2 patients underwent exploratory laparotomy to remove the migrated conduit. The incidence of accidental conduit migration was not significantly different between two groups $(p=0.50)$.

\section{DISCUSSION}

MHV reconstruction in LDLT using a modified right lobe graft results in improved recipient survival outcomes and contributes to a reduction in donor complications. Since MHV reconstruction was established as a routine procedure for most adult LDLT operations in our institution, the demand for sizable vein allografts has increased. In Korea, the number of deceased organ and tissue donors is very limited; thus, the supply of vein allografts is much smaller than the demand from LDLT. Prosthetic vascular grafts have no such supply limitations and, thus, offer very good availability. The long-term patency rates of the ringed Gore-Tex grafts were acceptably high; ${ }^{5,11}$ therefore, we previously used them whenever sizable vascular allografts were not available. After ringed Gore-Tex grafts became unavailable, they were substituted 
with Hemashield grafts in our institution. ${ }^{6,7}$

The physical features of Hemashield grafts are similar to those of ringed Gore-Tex vascular grafts. The circular pleats (Concentricrimp ${ }^{\mathrm{TM}}$, Maquet) of the Hemashield grafts prevent wall collapse caused by extrinsic compression. The wall is a thin, flexible structure of woven double-velour polyester; thus, it is easy to handle and suture the Hemashield grafts. Its bellows-like circular pleats offer flexible shortening or lengthening longitudinally to allow adjustment of the conduit length during anastomosis, and the morphological changes induced by graft regeneration are readily accommodated. The woven structure of these bovine collagen-impregnated grafts also prevents needle-hole bleeding; thus, the usual Prolene sutures can be used. Its longitudinal colored lines (Guideline ${ }^{\mathrm{TM}}$ stripe, Maquet) are useful for adjusting the alignment during anastomosis. The bovine collagen-impregnated and woven double-velour structure facilitates reduction of early luminal thrombus formation and tissue reaction at the anastomosis sites. The commercially available Hemashield Platinum vascular graft has a diameter of 10 or $12 \mathrm{~mm}$ and a length of $25 \mathrm{~cm}$, which are optimal dimensions for an MHV conduit.

We have previously tested other prosthetic vascular grafts. ${ }^{6}$ We found that ePTFE grafts with outer spiral-wound rings $\left(\operatorname{Impra}^{\mathrm{TM}}\right.$, Bard; New Providence, NJ, USA) provide flexibility in longitudinal length control, but products with a diameter $>10 \mathrm{~mm}$ are not currently in commercial production. A thin-walled ePTFE graft with an inner carbon lining (Impra Carboflo ${ }^{\mathrm{TM}}$, Bard) appears suitable for MHV reconstruction, but the commercially available product is only $10 \mathrm{~cm}$ in length. Owing to these critical inadequacies, the abovementioned prosthetic vascular grafts are not viable alternatives to ringed Gore-Tex grafts.

This study revealed that the short- and mid-term patency rates of Hemashield grafts are comparable to those of ringed Gore-Tex grafts. This is the most important point in this study because it indicates that ringed GoreTex grafts can be reliably replaced with Hemashield grafts. This is the first report to present the mid-term patency rates of Hemashield grafts in MHV reconstruction. The primary reasons for the high patency rates of Hemashield grafts include the large internal conduit diameter, circular pleats resistant to extrinsic compression, bridging allograft patch that reduces tissue reactions, and low-thrombogenic bovine collagen-impregnated lumen that induces slow construction of an endothelial cell-lined internal tunnel within the luminal thrombus. ${ }^{5,6,11}$

There were some cases of accidental migration of a Gore-Tex graft into the hollow viscera. ${ }^{5,6,11-13}$ A ringed Gore-Tex graft is converted to a rock-hard foreign body if the lumen is filled with thrombosis. Its accidental migration into the stomach or duodenum can induce lifethreatening complications; thus, the migrated conduit should be removed through re-exploration. We have previously reported that the incidence of ringed Gore-Tex conduit migration was $1.6 \%$ at 5 years, ${ }^{6}$ while in Taiwanese study, it was $1.5 \%{ }^{12}$ However, we have not encountered any cases of accidental migration of Hemashield grafts yet. As our observation period for Hemashield grafts was much shorter than that for ringed Gore-Tex grafts, longterm observation is necessary to assess the real risk of conduit-associated complications for Headshield grafts because all occluded prosthetic vascular grafts remain as foreign bodies. In our current analysis of morphological changes after thrombotic occlusion, thrombosed Hemashield grafts partially collapsed, forming a flattened foreign body, but the shape of ringed Gore-Tex grafts was unchanged. We conjecture that such differences in morphology may alter the incidence of accidental graft migration into the adjacent hollow viscera. The findings of this study suggest that Hemashield grafts are more suitable than ringed Gore-Tex grafts for MHV reconstruction considering their patency rates and incidence of conduit-associated complications.

This study has some limitations. This study was a single-center study, which could potentially introduce selection bias. The follow-up period was relatively short; thus, the incidence of conduit-associated complications was not completely evaluated.

In conclusion, Hemashield grafts used in MHV reconstruction demonstrated acceptably high short- and mid-term patency rates, no incidences of conduit migration, easy handling, and good flexibility for length adjustment. Therefore, we suggest that the Hemashield graft is the preferentially suitable prosthetic material for MHV reconstruction. 


\section{CONFLICT OF INTEREST}

No potential financial conflicts or other conflicts of interest exist for any of the authors of this article.

\section{ORCID}

Sang Hoon Kim: https://orcid.org/0000-0002-8025-1816

Shin Hwang: https://orcid.org/0000-0002-9045-2531

Minjae Kim: https://orcid.org/0000-0001-6743-0636

Tae-Yong Ha: https://orcid.org/0000-0001-9932-0212

Gi-Won Song: https://orcid.org/0000-0002-4235-0434

Dong-Hwan Jung: https://orcid.org/0000-0001-5984-023X

Chul-Soo Ahn: https://orcid.org/0000-0002-3844-3646

Deok-Bog Moon: https://orcid.org/0000-0002-8209-3540

Ki-Hun Kim: https://orcid.org/0000-0002-4016-0995

Gil-Chun Park: https://orcid.org/0000-0003-1631-3258

Sung-Gyu Lee: https://orcid.org/0000-0001-9161-3491

\section{AUTHOR CONTRIBUTIONS}

Conceptualization: SH. Data curation: CSA, DBM, KHK, SGL. Methodology: SHK, MK, TYH, GWS, DHJ, GCP. Visualization: SH. Writing - original draft: SH, SHK. Writing - review \& editing: SH.

\section{REFERENCES}

1. Hwang S, Lee SG, Lee YJ, Sung KB, Park KM, Kim KH, et al. Lessons learned from 1,000 living donor liver transplantations in a single center: how to make living donations safe. Liver Transpl 2006;12:920-927.

2. Hwang S, Lee SG, Ahn CS, Park KM, Kim KH, Moon DB, et al. Cryopreserved iliac artery is indispensable interposition graft material for middle hepatic vein reconstruction of right liver grafts. Liver Transpl 2005;11:644-649.

3. Sugawara Y, Makuuchi M, Akamatsu N, Kishi Y, Niiya T, Kaneko J, et al. Refinement of venous reconstruction using cryopreserved veins in right liver grafts. Liver Transpl 2004;10: 541-547.

4. Hwang S, Lee SG, Song GW, Lee HJ, Park JI, Ryu JH. Use of endarterectomized atherosclerotic artery allograft for hepatic vein reconstruction of living donor right lobe graft. Liver Transpl 2007; 13:306-308.

5. Hwang S, Jung DH, Ha TY, Ahn CS, Moon DB, Kim KH, et al. Usability of ringed polytetrafluoroethylene grafts for middle hepatic vein reconstruction during living donor liver transplantation. Liver Transpl 2012;18:955-965.

6. Park GC, Hwang S, Ha TY, Song GW, Jung DH, Ahn CS, et al. Hemashield vascular graft is a preferable prosthetic graft for middle hepatic vein reconstruction in living donor liver transplantation. Ann Transplant 2019;24:639-646.

7. Jeong IJ, Hwang S, Ha TY, Song GW, Jung DH, Park GC, et al. Technical refinement of prosthetic vascular graft anastomosis to recipient inferior vena cava for secure middle hepatic vein reconstruction in living donor liver transplantation. Ann Hepatobiliary Pancreat Surg 2020;24:144-149.

8. Ko GY, Sung KB, Yoon HK, Kim JH, Song HY, Seo TS, et al. Endovascular treatment of hepatic venous outflow obstruction after living-donor liver transplantation. J Vasc Interv Radiol 2002;13:591-599.

9. Ko GY, Sung KB, Yoon HK, Kim KR, Kim JH, Gwon DI, et al. Early posttransplant hepatic venous outflow obstruction: long-term efficacy of primary stent placement. Liver Transpl 2008;14:1505-1511.

10. Ha TY, Hwang S, Jung DH, Ahn CS, Kim KH, Moon DB, et al. Complications analysis of polytetrafluoroethylene grafts used for middle hepatic vein reconstruction in living-donor liver transplantation. Transplant Proc 2014;46:845-849.

11. Papanicolaou G, Beach KW, Zierler RE, Detmer PR, Strandness DE Jr. Hemodynamics of stenotic infrainguinal vein grafts: theoretic considerations. Ann Vasc Surg 1995;9:163-171.

12. Hsu SC, Thorat A, Yang HR, Poon KS, Li PC, Yeh CC, et al. Assessing the safety of expanded polytetrafluoroethylene synthetic grafts in living donor liver transplantation: graft migration into hollow viscous organs- diagnosis and treatment options. Med Sci Monit 2017;23:3284-3292.

13. Sultan AM, Shehta A, Salah T, Elshoubary M, Wahab MA. Spontaneous migration of thrombosed synthetic vascular graft to the duodenum after living-donor liver transplantation: a casereport. Int J Surg Case Rep 2018;45:42-44. 